\title{
COLLABORATIVE WRITING IN EFL CONTEXT: A LITERATURE REVIEW OF RESEARCH REPORTS IN THE LAST DECADE*
}

\author{
Ani Susanti \\ Universitas Ahmad Dahlan Yogyakarta \\ e-mail: ani.susanti@pbi.uad.ac.id
}

\begin{abstract}
The 4 Cs $21^{\text {st }}$ century skills framework has included collaboration as one of the critical skills for now and future generation living. In EFL context, studies about collaboration are often connected with collaborative writing $(\mathrm{CW})$. This strategy has been more popular especially in higher education as academic writing and collaboration skills development strategy. Numbers of studies reported not only the outcome but also the process of collaborative writing. This paper synthesizes research reports in the last decade collected from online publication including unpublished thesis and dissertation as well as articles in journals related to language education. Inspired by Dillenbourg (1996), this synthesis report is organized into four dimensions; focus on effect, condition, interaction, and technology use. Finally, some possible future research questions are pointed out.
\end{abstract}

Keywords: collaboration, academic writing, Collaborative Writing, EFL, higher education

\section{Introduction}

Collaboration has been more familiar in education since it's one of the skills in 21 $1^{\text {st-century living }}$ (Mercier, 2015). There are two main factors contribute to the popularity of collaboration skills. First, research advises that people with outstanding collaboration skills perform better in school. For instance, an experimental study exploring the effects of teamskills training in university context concludes that college students trained how to work together (e.g., planning, decisions making as a group, objectives setting, time management, roles agreement, and a positive group environment creation) show more effective collaboration performance (Prichard, Startford, \& Bizo, 2006). The other study reports that undergraduate students involved in web-based collaborative writing tasks achieved statistically significant more learning results in their writing score than did the single writing. Bikowski \& Vithanage, 2016). Thus, developing collaboration 
skills contribute to better learning gains.

Second, research suggests that people with more collaboration skills are more recognized in the workplace. For instance, Chen (2002) found that in Taiwan self-reported skills in adaptability, coordination, decision-making, leadership, and interpersonal skills were confidently linked with performance appraisal scores, salaries, and bonuses. The skills to work in teams are significantly needed in most of the work organization. Therefore, Salas, Shuffler, Thayer, Bedwell \& Lazzara (2014) synthesized studies about teams in the organization and provide a practical guide to understand and improve teamwork quality. In other words, having better collaboration skills lead to better recognition in the workplace and also contributes to the organization development.

Therefore, because of the good value of collaboration skills in the students' future education and work, it looks prominent to believe that social interaction skills should to be highlighted in schools and need be explicitly taught rather than selflearning. Familiarity and involvement to collaborate in schools may characterize the development of learners' social interaction skills. As written by Brown (1994: 159) that "the best way to learn to interact is through interaction itself."

In EFL context, collaboration often appears in writing skills learning. While writing is traditionally considered as an individual activity, it is quite common that collaborative writing tasks are instructed in higher education context for example in forms of peers or group work for an essay or academic writing assignments. Not only in the classroom, in real life have most people recently done collaboration in producing written works.

Storch (2005, 2011) defines collaborative writing $(\mathrm{CW})$ as a joint production or co-authoring of a text by two or more writers. She notes that $\mathrm{CW}$ emphasizes on the joint ownership because the writers engage in the whole writing process or on partial writing activities such as group planning or peer editing. The typical use of $\mathrm{CW}$ is much informed by both theoretical and pedagogical justification.

From the theoretical consideration, the use of the use of $\mathrm{CW}$ in L2 learning refers to the Vygostky's social constructivist perspective in human cognitive development. According to Vygotsky (1978: 88) "human learning presupposes a specific social nature and a process by which children 
grow into the intellectual life those around them." The concept of Zone Proximal Development (ZPD) introduced by Vygotsky (1978: 86) suggests that ZPD is the gap between the actual independent developmental level and the level of potential development as scaffolded through problem-solving under adults' supervision or collaboration with more capable peers. This perspective highlights that social interaction is central to contribute the learners' cognitive development.

Inspired by the Vygotskian perspective, Thorne (2005) and Lantolf and Thorne (2007: 216) explain the basic constructs of sociocultural theory (SCT) called mediation and regulation, internalization, and the ZPD in Second Language Acquisition (SLA). In line with SCT conceptualization, Swain (2006: 106) asserts that the process of interaction is mediated by psychological tools, of which language is one of the most important; cognition and recognition of experience, as well as knowledge, are mediated through speaking and writing.

From

perspectives, pedagogical demonstrated research has collaboration that facilitates

language

(McDonough, 2004; Storch, 2004).
This paper reviews several studies in the last decade concerning on CW in the context of (English) second language learning in higher education. The organization of the review follows the four dimensions suggested by Dillenbourg (1996: 195) in explaining the evolution of research on collaborative learning, which is focusing on effect, condition, interaction, and technology use.

\section{CW Studies Focus on Effect}

CW studies focusing on effect concern with vocabulary acquisition and the quality of written text as the outcome of the collaboration activities. Kim (2008) and Nassaji and Tian (2010) informed that CW learners got better vocabulary test comparing to that of individual learners. While, it's been reported that CW has affected the writing accuracy, complexity, and fluency. Khatib \& Meihami (2015), Shehadeh (2011), and Utami (2014) reported that the accuracy of the students writing performance is positively affected by the CW activities. These studies confirm that $\mathrm{CW}$ influences the quality of five analytical writing aspects (content, organization, vocabulary, grammar/language use, and mechanics), even though Shehadeh (2011) noted that the effect of CW to grammar and mechanics aspect is not statistically significant. 
Shehadeh (2011) conducted an experimental study in a large university in United Arab Emirates involving two intact groups to investigate the effectiveness of $\mathrm{CW}$. One group consisted of 18 students was considered as the experimental group, and the other group consisted of 20 students was considered as control group. In this study, the participants had pretest and posttest, which in the pretest the participants were instructed to write 100-wordparagraph about their house, while in the post-test the participants were required to write 100-wordparagraph about their campus. Shehadeh's study lasted for 16 weeks. In the control group, the writing tasks were done individually, while in experimental group the tasks were carried out in pairs. From the study it was found that $\mathrm{CW}$ has a significant effect on the aspect of content, organization, and vocabulary; but not significant for grammar and mechanics.

Instead of using an analytical rubric, another study by Wigglesworth and Storch (2009) measured the accuracy of the students writing performance through quantitative calculation on the percentage of error-free T-Units and error-free clauses. Wigglesworth and Storch (2009) compared the result of individual versus pair writing and found that collaboration impacted positively on accuracy. This means that the pair work writing has a higher percentage of error-free $\mathrm{T}$ Units and error-free clauses.

Different from the accuracy aspect, the studies on the effect of $\mathrm{CW}$ to complexity aspect informed that collaboration appears to have no impact on grammatical complexity and there are no statistically significant differences between the texts produced by the pairs and those produced by the individuals. This finding recommends further research to investigate the other construct to measure complexity. Also, the other underexplored area calling for further research is the effect of $\mathrm{CW}$ to students' fluency in writing (i.e., length of words) as suggested by Biria and Jafari (2013) and Wigglesworth and Storch (2009).

Along with the investigations of $\mathrm{CW}$ effects to vocabulary acquisition and students' writing quality, the influence of $\mathrm{CW}$ tasks in shaping the students and teachers' perceptions toward $\mathrm{CW}$ has been explored (Al Ajmi \& Ali, 2014; Dabao \& Blum, 2013; Lina \& Maarof, 2013; Shehadeh, 2011). Although some challenges were reported for example unproductive CW group members, conflicting opinions, bossy group members (Al Ajmi \& Ali study, 2014) and class size, time constraints, and 
teachers' ability to facilitate and guide the $\mathrm{CW}$ process (Lina \& Maarof, 2013); studies on perception toward $\mathrm{CW}$ tend to show that most students and teachers generally have positive views to $\mathrm{CW}$ and perceive to get more benefits from $\mathrm{CW}$ activities.

\section{CW Studies Focus on Condition}

$\mathrm{CW}$ studies focusing on condition concern with the role of factors contributing to the quality of collaboration and the outcome of $\mathrm{CW}$ for example language proficiency (Ajideh, Leitner, \& Yazdi-Amirkhiz, 2016; Watanabe and Swain, 2007), pattern of interaction (Watanabe and Swain, 2007), number of participants (Dabao, 2012; Storch, 2002 a, 2002b, 2004, 2007, 2008), the task variation (McDonough and Fuentes, 2015; Kim and McDonough, 2011; Lassiter, 2014), and member personality, collaboration experience as well as cultural values (Rezeki, 2016).

Watanabe and Swain (2007) examined 12 Japanese learners in a non-credit ESL programme at a Canadian university which were grouped based on their English proficiency. They aimed to explore the effects of proficiency differences and patterns of interaction on L2 learning through the examination of collaborative dialogue and post-test performance. The findings suggested that the core-high pairs produced a higher frequency of language-related episodes (LREs) than that of the corelow pairs. However, the core participants learned more when working with lower proficiency peers than higher proficiency peers, suggesting that there is indeed value for more proficient students to be paired with less proficient peers. Watanabe and Swain (2007) claimed that proficiency differences do not necessarily affect the nature of peer assistance and L2 learning because learning occurs in interaction, not as a result of interaction. However, different findings on the role of language proficiency are reported by Ajideh, Leitner, \& Yazdi-Amirkhiz (2016) and Kim and McDonough (2011). Their study found that language proficiency does affect the problem-solving process during collaboration.

Beside proficiency differences, number of participants in $\mathrm{CW}$ has been known as one of the influencing factors. Confirming the previous intensive studies reported by Storch (2002, 2004, 2007, 2008) and Watanabe and Swain (2007) about the role of number of participants and patterns of interaction in conditioning the quality of collaboration, Dobao (2012) compared the writing performance of intermediate learners by groups of four learners, pairs, and individual 
learners. This study focused on the effect of the number of participants to the fluency, complexity, and accuracy of the produced written texts. Besides, Dabao's study (2012) also investigated the characteristics of the spoken interaction between the pairs and the groups as they collaborate during the writing process. The analysis of interaction through the language-related episodes (LREs) revealed that pairs produced fewer LREs and a lower percentage of correctly resolved LREs than groups. Finally, the texts written by the groups were more accurate compared to those written by pairs or individuals. These findings are in line with Wiggleworth and Storch (2012) who argue that learners doing pair writing activities can improve learning by providing opportunities for discussing of language.

Beside language proficiency, number of participants, and patterns of interaction, tasks variation may impact the CW process. Kim (2009) argued the role of task complexity on learner-learner interaction. In line with Kim, McDonough and Fuentes (2015) compared the difference between problem/solution and cause/effect paragraphs produced by the students collaboratively and individually. The result showed that cause/effect writing tasks lead to higher complexity paragraphs performed by collaborative pairs. Another collaborative tasks study found that jigsaw, text construction, and dictogloss were effective in conditioning the students eliciting more language-related episodes (LREs) (De la Colina and Garcia Mayo, 2007 in Storch, 2011). Then, informed by the role of tasks variation in promoting $\mathrm{CW}$, Lassiter (2014) proposes a writing module for undergraduate EFL learners using genre-based and collaborative learning approach. However, the other study found that there's no strong connection between prewriting task discussions and the writing outcome (Neuman and McDonough, 2015). Neuman and McDonough (2015) investigated the relationship between interaction during prewriting tasks and students' written texts in an EAP program at Concordia University in Montreal, Canada. Being informed that some learners may prefer to work individually rather than in a group, Neuman and McDonough (2015) let the learners decide their preferences. While, investigation to group interactions showed that structured collaborative prewriting tasks lead to student talks about the content and organization, but there's a less convincing relationship between prewriting task discussions and the quality of students' written text. 
Considering that most factors known are more external, Chen (2015) focuses on the internal factors to approach CW, students' cognitive knowledge, and attitude. In addition, Rezeki (2016) conducted a qualitative study and mentioned several other attributes affecting the process of $\mathrm{CW}$ such as member personality, collaboration experience, and cultural values.

In sum, CW studies focusing on condition have informed several internal and external attributes affecting the process and result of CW. However, further exploration of the other psychological factors such as motivation, anxiety, learning styles and strategies (Dornyei, 2005) possibly contributes more insights on CW theoretically and pedagogically. Additionally, within the framework of $21^{\text {st }}$-century learning (Mercier, 2015), more empirical findings informing the connection between $\mathrm{CW}$ process/outcome and classroom facilities/design might be advantageous.

\section{CW Studies Focus on Interaction}

CW studies focusing on interaction emphasize on the interaction during the process of collaboration including metatalk analysis on the produced LREs and the use of L1 language in pair and group discussion. Studies concerning on metatalk in group interaction during CW activities are reported by Guiterezz (2008) and Storch (2008). These studies observed the produced LREs to know the degree of engagement so that more facilitative interaction pattern could be explained. However, these two studies were conducted in English speaking countries, Canada and Australia. While the study on LREs analysis in non-English speaking is very limited, one of them is Aldosari's dissertation. This study found that there was an extensive use of L1 in pair work activity and that task type had a more significant impact on the amount of L1 used than proficiency pairing. L1 was principally used for task management and to facilitate deliberations over vocabulary. About task management, L1 seems to reflect the kind of relationship the learners made. About vocabulary deliberations, L1 was used to provide explanations to peers and for private speech (Aldosari, 2008 in Storch, 2011; and Storch \& Aldosari, 2010). Considering the limitation of LREs analysis studies, further exploration using LREs analysis approach should be encouraged to gain more explanation about the nature of $\mathrm{CW}$ interaction, particularly in nonEnglish speaking countries. 
CW Studies Focus on Technology Use

CW studies focusing on technology use deal with the utilization of web 2.0 technology to facilitate online collaboration. Different kinds of platform to support collaborative writing tasks are studied such as Blog (Amir, Ismail, \& Hussin (2011), Wiki (Aydin \& Yildiz, 2014; Chaoa \& Lo, 201; Elola, 2010; Larrañaga, 2012), Google Doc (Bikowski \& Vithanage, 2016; Handayani, 2012; Kessler, Bikowski, and Boggs, 2012), Viber (Challob, Abu Bakar \& Latif, 2016), Etherpad (Brodahl, Hadjerrouit \& Hansen, 2011), and Blackboard (Choi, 2014). Although most of the studies give the impression that those platforms are beneficial, it is lack of information on which platform is preferable by students in EFL context within a various degree of ICT literacy.

The studies on web 2.0 technology investigated several aspects for example the students perceptions on how certain online collaborative platform can facilitate language learning (Amir, Ismail, \& Hussin, 2011; Aydin \& Yildiz, 2014; Larrañaga, 2012), attitudes toward the use of technology for $\mathrm{CW}$ (Brodahl, Hadjerrouit \& Hansen, 2011), how technology affect the accuracy, complexity, and fluency (Elola, 2010), the constraints
(Handayani, 2012), teachers' ICT familiarization (Cahyono \& Mutiaraningrum, 2016), and the role of planning and preparation (Choi, 2014), as well as the interaction nature (Choi, 2014; Kessler, Bikowski, and Boggs, 2012). Even though numerous studies explain the nature of interaction in $\mathrm{CW}$ and the outcome of the online collaborative writing task, it seems less information explaining how individual and psychological differences affect the students' engagements to the use of web 2.0 technologies for $\mathrm{CW}$ purpose.

\section{Conclusion}

Emerged studies on $\mathrm{CW}$ in EFL context in higher education in the last decades has been organized into four smaller areas related to effect, condition, interaction, and technology used. Those studies were conducted in various research designs but mostly experimental and case studies. Reviewing those studies shares several possible future investigations. First, studies on the effect of $\mathrm{CW}$ to writing quality have focused more on accuracy rather than on complexity and fluency. This synthesis calls more exploration (possibly experimental design) on the other constructs to explain the effect of $\mathrm{CW}$ in writing complexity and fluency. Second, there are both 
internal and external factors contribute to the process and outcome of CW tasks, however, more explanation (perhaps through causal comparative or correlational studies) seems needed primarily on the role of psychological differences (such as motivation, learning style, and writing anxiety) as well as classroom design / facilities. Third, further studies on LREs quantitative and qualitative analysis in CW interaction in EFL context within non-English speaking countries might contribute to broader understanding of $\mathrm{CW}$ interaction pattern. Finally, further exploration through experimental or case studies to understand the role of individual differences in engaging web-based CW seems weighty to elaborate how advance technology has a place in EFL writing skill development.

\section{REFERENCES}

Ajideh, Parviz; Leitner, Gerhard; \& Yazdi-Amirkhiz, Seyed Yasin. 2016. The Influence of Collaboration on Individual Writing Quality: The Case of Iranian vs. Malaysian College Students. Journal of English Language Teaching and Learning, 17, 1- 24.

Al Ajmi, Ahmed Ali Saleh \& Ali, Holi Ibrahim Holi. 2014. Collaborative Writing in Group Assignments in an EFL/ESL Classroom. English Linguistics Research, 3 (2), 1 - 17. Amir, Zaini; Ismail, Kemboja \& Hussin, Supyan. 2011. Blogs in Language Learning: Maximizing Students' Collaborative Writing. Procedia Social and Behavioral Sciences, 18, 537-543.

Aydın, Zeliha \& Yıldız, Senem. 2014. Using Wikis to Promote Collaborative EFL Writing. Language Learning $\mathcal{E}$ Technology, 18 (1) 160-180.

Bikowski, Dawn \& Vithanage, Ramyadarshanie. 2016. Effects of Web-Based Collaborative Writing on Individual L2 Writing Development. Language Learning E Technology, 20 (1), 79-99.

Biria, Reza \& Jafari, Sahar. 2013. The Impact of Collaborative Writing on the Writing Fluency on Iranian EFL Learners. Journal of Language Teaching and Research, 4 (1), $164-175$.

Brodahl, Cornelia; Hadjerrouit, Said, \& Hansen, Nils Kristian. 2011. Collaborative Writing with Web 2.0 Technologies: Education Students' Perceptions. Journal of Information Technology Education: Innovations in Practice, 10, 74 103.

Brown, HD. 1994. Teaching by principles: an interactive approach to language pedagogy. Prentice Hall, Eaglewood Cliffs. 
Cahyono, Bambang Yudi \& Mutiaraningrum, Ira. 2016. Indonesian EFL Teachers' Familiarity with and Opinion on the Internet-Based Teaching of Writing. English Language Teaching, 9 (1), 199 - 208.

Challob, Ala'a Ismael; Abu Bakar, Nadzrah \& Latif, Hafizah. 2016. Collaborative Blended Learning Writing Environment: Effects on EFL Students' Writing Apprehension and Writing Performance. English Language Teaching, 9 (6), 229 - 241.

Chaoa, Yu-Chuan Joni \& Lo, HaoChang. 2011. Students' Perceptions of Wiki based Collaborative Writing for Learners of English as a Foreign Language. Interactive Learning Environments, 19 (4), 395-411.

Chen, Wenting. 2015. How Knowledge and Attitude Affect ESL Students Collaborative Writing Outcomes. Unpublished Doctoral Dissertation. University of Toledo.

Choi, Jessie. 2014. Online Peer Discourse in a Writing Classroom. International Journal of Teaching and Learning in Higher Education, 26 (2), 217 - 231.

Dillenbourg, P., Baker, M., Blaye, A., \& O'Malley, C. 1996. The Evolution of Research on Collaborative Learning. In E.
Spada \& P. Reiman (Eds.), Learning in humans and machine: Towards an interdisciplinary learning science (pp. 189-211). Oxford: Elsevier. Dobao, Ana Ferna'ndez \& Blum Avram. 2013. Collaborative Writing in Pairs and Small Groups: Learners' Attitudes and Perceptions. System, 41, 365 - 378. Dobao, Ana Ferna'ndez. 2012. Collaborative Writing Tasks in the L2 Classroom: Comparing Group, Pair, and Individual Work. Journal of Second Language Writing, 21, 40-58.

Dornyei, Zoltan. 2005. The Psychology of the Language Learner: Individual Differences in Second Language Acquisition. Mahwah, New Jersey: Lawrence Erlbaum Associates.

Elola, Idoia \& Oskoz Ana. 2010. Collaborative Writing: Fostering Foreign Language and Writing Conventions Development. Language Learning \& Technology, 14 (3), 51-71.

Guti'Errez, Xavier. 2008. What Does Metalinguistic Activity In Learners' Interaction During A Collaborative L2 Writing Task Look Like? The Modern Language Journal, 92 (iv), 519-537.

Handayani, Nani Sri. 2012. Emerging Roles In Scripted Online Collaborative Writing In Higher 
Education Context. Procedia Social and Behavioral Sciences, 67, $370-379$.

Kessler, Greg; Bikowski, Dawn \& Boggs, Jordan. 2012. Collaborative Writing Among Second Language Learners In Academic Web-Based Projects. Language Learning $\mathcal{E}$ Technology, 16 (1), 91 - 109.

Khatib, Mohammad \& Meihami, Hussein. 2015. Languaging and Writing Skill: the Effect of Collaborative Writing on EFL Students' Writing Performance. Advances in Language and Literary Studies, 6 (1), 203 - 211.

Kim, YouJin \& McDonough, Kim. 2011. Using Pretask Modelling to Encourage Collaborative Learning Opportunities. Language Teaching Research, 15 (2), 183-199.

Kim, Youjin. 2008. The Contribution of Collaborative and Individual Tasks to the Acquisition of L2 Vocabulary. The Modern Language Journal, 92 (1): 114-130.

Kim, YouJin. 2009. The Effects of Task Complexity on Learnerlearner Interaction. System, 37, 254-268.

Lantolf, J. \& Thorne, S. L. 2007. Sociocultural Theory and Second Language Learning. In. B. van Patten \& J. Williams (eds.), Theories in Second Language
Acquisition (pp. 201-224).

Mahwah, NJ: Lawrence Erlbaum. Larrañaga, Nagore Ipiña. 2012. The Impact of Contextual Factors in the Development of Collaborative Writing in CLIL-POL Settings at Tertiary Level. Unpublished Doctoral Thesis. Mondragon Unibertsitatea.

Lassiter, Misty R.. 2014. Collaborative and Genre-Based Writing in the L2. Writing Classroom. Unpubished Master's Projects. University of San Francisco.

Lina, Ong Poh \& Maarof, Nooreiny. 2013. Collaborative Writing in Summary Writing: Student Perceptions and Problems. Procedia - Social and Behavioral Sciences, 90, $599-606$.

McDonough, Kim \& Fuentes, César García. 2015. The Effect of Writing Task and Task Conditions on Colombian EFL Learners' Language Use. TESL Canada Journal. 32, (2), 67 - 79.

McDonough, Kim. 2004. Learnerlearner Interaction During Pair and Small Group Activities in a Thai EFL Context. System, 32, 207-224.

Mercier, Emma. 2015. The Four Ts of the Collaborative Classroom. Orchestrated Collaborative Classroom Workshop, Githenburg, Sweden. 
Nassaji, Hossein \& Tian, Jun. 2010. Collaborative and Individual Output Tasks and Their Effects on Learning English Phrasal Verbs. Language Teaching Research, 14: 397 - 419.

Neumann, Heike \& McDonough, Kim. 2015. Exploring Student Interaction During collaborative Prewriting Discussions and its Relationship to L2 Writing. Journal of Second Language Writing, 27, 84-104.

Prichard, J.S., Stratford, R.J., \& Bizo, L.A. 2006. Team-skills training enhances collaborative learning. Learning and Instruction. 16 (3), 256 - 265.

Rezeki, Yanti Sri. 2016. Indonesian English-as-A-Foreign-Language (EFL) Learners' Experiences in Collaborative Writing. Unpublished Doctoral

Dissertation. University of Rochester.

Salas, Eduardo; Shuffler, Marissa L., Thayer, Amanda L., Bedwell, Wendy L., \& Lazzara, Elizabeth H.2014. Understanding and ImprovingTeamwork in Organizations: A Scientifically Based Practical Guide. Human Resource Management. Published online in Wiley Online Library. DOI: 10.1002/hrm 21628
Shehadeh, Ali. 2012. Effects and Student Perceptions of Collaborative Writing in L2. Journal of Second Language Writing, 20, 286-305.

Storch, Neomy \& Aldosari, Ali. 2010. Learners' Use of First Language (Arabic) in Pair Work in an EFL Class. Language Teaching Research, $14,355-375$.

Storch, Neomy. 2002. Relationships Formed in Dyadic Interaction and Opportunity for Learning. International Journal of Educational Research, 37, 305-322.

Storch, Neomy. 2004. Using Activity Theory to Explain Differences in Patterns of Dyadic Interactions in an ESL Class. The Canadian Modern Language Review, 60, 457480.

Storch, Neomy. 2005. Collaborative Writing: Product, Process, and Students' Reflections. Journal of Second Language Writing, 14, 153173.

Storch, Neomy. 2007. Investigating the Merits of Pair Work on a Text Editing Task in ESL Classes. Language Teaching Research, 11(2), 43-159.

Storch, Neomy. 2008. Metatalk in a Pair Work Activity: Level of Engagement and Implications for Language Development. Language Awareness, 17(2), 95 114. 
Storch, Neomy. 2011. Collaborative Writing in L2 Contexts: Processess, Outcomes and Future Directions. Annual Review of Applied Linguitics, 31, 275 - 288.

Swain, Merill. 2006. Languaging, Agency and Collaboration in Advanced Second Language Proficiency. In Byrnes H. (Ed.), Advanced Language Learning: The Contribution of Halliday and Vygotsky, (pp. 95-108). LondonNew York: Continuum.

Thorne, Steven L.. 2005.

Epistemology, Politics, and Ethics in Sociocultural Theory. The Modern Language Journal, 89 (iii), $393-409$.

Utami, Amrih . 2014. English Education in EFL Context: Integrated Approach for Collaborative Writing in the University Level. Journal of Education, 7 (1), 40 - 50.

Vygotsky, L.S. 1978. Mind in Society.

The development of higher psychological processes (M.Cole, V.John-Steiner, S.Scribner, \& E.Souberman, Eds). Cambridge, MA: Harvard University Press.

Watanabe, Yuko and Swain, Merrill. 2007. Effects of Proficiency Differences and Patterns of Pair Interaction on Second Language Learning: Collaborative Dialogue Between Adult ESL Learners.
Language Teaching Research, 11 (2), 121-142.

Wigglesworth, Gillian \& Storch, Neomy. 2009. Pair Versus Individual Writing: Effects on Fluency, Complexity and Accuracy. Language Testing, 26 (3), 445-466.

Wigglesworth, Gillian \& Storch, Neomy. 2012. What Role for Collaboration in Writing and Writing Feedback. Journal of Second Language Writing, 21, 364374. 